1999

\title{
Nutrition and ageing in Africa
}

Karen E. Charlton

University of Cape Town, karenc@uow.edu.au

\section{Publication Details}

Charlton, K. E. 1999, 'Nutrition and ageing in Africa', Asia Pacific Journal of Clinical Nutrition, vol. 8, no. 4, pp. $280-281$.

Research Online is the open access institutional repository for the University of Wollongong. For further information contact the UOW Library: research-pubs@uow.edu.au 


\title{
Nutrition and ageing in Africa
}

\begin{abstract}
Although the proportion of elderly people in African populations is much smaller than that in developed countries, the absolute numbers of older Africans are rapidly increasing. The huge majority of Africans live in poor economic circumstances and few countries are able to offer social assistance programs. The health and wellbeing of older persons largely depend on the integral existence of informal services, social support networks and kin support. African gerontologists have urged social welfare policy makers to take cognizance of self-organized intergenerational help systems already present on the continent, and to make public-sector finance available to support these systems. Nutrition service programs should be included in such support systems
\end{abstract}

\section{Keywords}

africa, ageing, nutrition

\section{Disciplines}

Medicine and Health Sciences | Social and Behavioral Sciences

\section{Publication Details}

Charlton, K. E. 1999, 'Nutrition and ageing in Africa', Asia Pacific Journal of Clinical Nutrition, vol. 8, no. 4, pp. 280-281. 


\section{Nutrition and ageing in Africa}

Karen Charlton MPhil (Epidemiol), MSc, SRD

Nutrition and Dietetics Unit, Faculty of Health Sciences, University of Cape Town, Observatory 7925, South Africa

Although the proportion of elderly people in African populations is much smaller than that in developed countries, the absolute numbers of older Africans are rapidly increasing. The huge majority of Africans live in poor economic circumstances and few countries are able to offer social assistance programs. The health and wellbeing of older persons largely depend on the integral existence of informal services, social support networks and kin support. African gerontologists have urged social welfare policy makers to take cognizance of self-organized intergenerational help systems already present on the continent, and to make public-sector finance available to support these systems. Nutrition service programs should be included in such support systems.

These themes were some of those deliberated in the Third African Regional Workshop of the African Gerontological Association (AGES International) held in Nairobi, Kenya from 12 to 17 April 1999. The AGES is presently chaired by Professor Nana Apt, Head of the Centre for Social and Policy Studies at the University of Ghana. Dr Alexandre Kalache, Chief, Ageing and Health, World Health Organization (WHO), gave the keynote address, 'Healthy ageing as a key development issue for Africa'. The Workshop, which was attended by 140 participants from 11 countries, showed that Africa has become an important new global player in the field of ageing, nutrition and health status, and that there is much to be learned from the continent in this regard.

Issues pertinent to healthy ageing and nutrition in Africa are outlined below:

\section{Food security}

Much of Africa is plagued by drought, famine, civil war, poverty and, more recently, the devastating effects of the AIDS epidemic. As a result of these problems food is scarce and is regarded as a priority basic need. Non-governmental organizations (NGOs), such as HelpAge International, play an important role in promoting meals programs and in developing food security initiatives. These international agencies work together with local NGOs and church groups in various countries. The regional office of HelpAge International is in Nairobi (the headquarters are in London). African countries in which there are HelpAge branches include Zimbabwe, Kenya, Tanzania, Ghana and South Africa.

\section{Poverty/social security}

Only two countries in Africa, South Africa and Namibia, provide formal economic support for older citizens. In South Africa, nearly $90 \%$ of elderly blacks receive a non-contributory, means-tested, state old-age pension which is paid monthly. The social pension contributes substantially to household budgets and pension monies are used collectively to support kin (three generations commonly coreside in African households), food being the major expenditure item. A large survey, is currently underway to investigate the impact of South Africa's state pension scheme on the health, wellbeing, coping strategies and household income and expenditure of not only pensioners but also other household members. The pilot study, funded by the US National Institute of Aging, has recently been completed.

\section{Indicators of malnutrition}

HelpAge International and the London School of Hygiene and Tropical Medicine have recently conducted a three-centre study in subjects aged 50 years and over (Rwandan refugees in Tanzania; rural elderly in Malawi; and slum dwellers in India) in order to identify anthropometric indicators of 
malnutrition for use in elderly people in developing countries. A summary of the findings has been published and is available from Karen Peachey, HelpAge International (helpage@net2000ke.com).

\section{Urbanization, nutrition transition and emergence of chronic diseases}

The nutrition transition Africans (i.e. those associated with increasing urbanization) will be accompanied by an increase in chronic diseases of lifestyle in present and future cohorts.

Preliminary data from a birth cohort study is showing that at the age of 5 years black African children in Johannesburg already have higher blood pressure levels than age-matched white children. Research efforts to improve the health of future elderly need to focus on the nutrition transition. An International Life Sciences Institute (ILSI)/International Union of Nutritional Sciences (IUNS) Urban Nutrition Workshop was held in Durban, South Africa from 5 to 7 March 1999, in conjunction with local affiliated nutrition bodies. The topic, 'Urban Nutrition: Lifespan and Lifestyle Issues for Africa', incorporated three broad age bands, namely, childhood, adulthood and later life. The IUNS Committee on Nutrition and Ageing was represented in the workshop by three members: Professor Mark Wahlqvist (Australia), Dr Noel Solomons (Guatemala) and Professor Karen Charlton (South Africa). The workshop was an historic

event as it was the first of its kind to be hosted in an African country.

\section{Health services/traditional healers}

A finding that emerged from the AGES workshop was that the preferred treatment agency for older Africans, especially in rural areas, is the traditional healer or sangoma. A strong reason for older persons' preference for using these agents appears to be related to good communication channels between healer and patient, and a mutually negotiated 'diagnosis' and treatment regimen, as well as a social explanation that is provided for an illness. Similarly, reliance on the use of herbal remedies to treat and prevent illness, as well as the contribution of indigenous plant sources to nutrient intake, warrants inclusion in the methodology of any dietary or health survey of older African populations. In this regard, an Institute of Traditional Medicine (TRAMED) has been established at the University of Cape Town and a database of the chemical composition and reported uses of indigenous plants is being compiled.

\section{Older women}

In African culture, the grandmother is a central figure in the daily management of the household, responsible for housework, food purchases, meal preparation and child care. In rural areas, women are in addition responsible for tilling the soil, planting crops, growing food, and more. Thus, nutrition education activities targeted at older female members of households may impact on the family unit as a whole.

\section{Research-networking opportunities}

There are a number of initiatives in the African region which include nutrition, health and ageing as a primary focus of research. The African Foundation for Research and Interdisciplinary Training in Ageing (AFRITA) is based in Harare, Zimbabwe. The Director of AFRITA, Dr Adrian Wilson, has recently been appointed to the Chair of Geriatrics at the University of Cape Town (UCT). Professor Wilson is committed to conducting nutrition-related research, in conjunction with UCT's Nutrition and Dietetics Unit, headed by Professor Karen Charlton. Also based in the Faculty of Health Sciences of the University of Cape Town is the only dedicated research centre on ageing in Africa, the Human Sciences Research Council/Universityof Cape Town Centre for Gerontology. Networking links and collaboration with other African researchers, as well as with researchers in countries elsewhere, are urgently needed in order to allow cross-cultural perspectives on ageing to be strengthened. 


\section{Useful contact details}

The President (and secretariat)

Professor Nana Apt

African Gerontological Society (AGES International)

PO Box 01803

Osu-Accra, Ghana

Email:csps@africaonline.com.gh

The Director

Prof. Adrian Wilson

AFRITA

PO Box 19

Harare

Zimbabwe

Email: awilson@uctgsh1.uct.ac.za

The Director

Dr Monica Ferreira

HSRC/UCT Centre for Gerontology

Faculty of Health Sciences

University of Cape Town

Observatory 7925

South Africa

Email: gerontol@anat.uct.ac.za

The Head

TRAMED

Department of Pharmacology

University of Cape Town

Groote Schuur Hospital

Observatory 7925

South Africa

Email: bcampbel@uctgsh1.uct.ac.za 